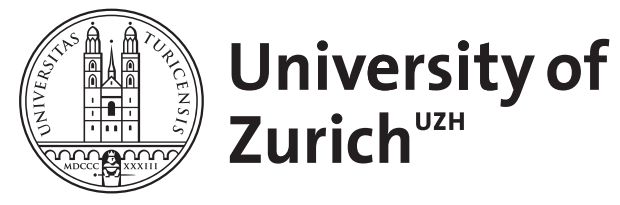

The impact of body mass index and gender on the development of infectious complications in polytrauma patients

\author{
Mica, L ; Keller, C ; Vomela, J ; Trentz, O ; Plecko, M ; Keel, M J
}

DOI: https://doi.org/10.1007/s00068-013-0300-8

Posted at the Zurich Open Repository and Archive, University of Zurich ZORA URL: https://doi.org/10.5167/uzh-78908

Journal Article

Published Version

Originally published at:

Mica, L; Keller, C; Vomela, J; Trentz, O; Plecko, M; Keel, M J (2014). The impact of body mass index and gender on the development of infectious complications in polytrauma patients. European Journal of Trauma and Emergency Surgery, 40(5):573-579.

DOI: https://doi.org/10.1007/s00068-013-0300-8 


\title{
The impact of body mass index and gender on the development of infectious complications in polytrauma patients
}

\author{
L. Mica • C. Keller • J. Vomela • O. Trentz • \\ M. Plecko • M. J. Keel
}

Received: 14 February 2013/Accepted: 19 May 2013/Published online: 11 June 2013

(C) Springer-Verlag Berlin Heidelberg 2013

\begin{abstract}
Purpose The aim was to test the impact of body mass index (BMI) and gender on infectious complications after polytrauma.

Methods A total of 651 patients were included in this retrospective study, with an Injury Severity Score (ISS) $\geq 16$ and age $\geq 16$ years. The sample was subdivided into three groups: BMI $<25 \mathrm{~kg} / \mathrm{m}^{2}$, BMI $25-30 \mathrm{~kg} / \mathrm{m}^{2}$, and BMI $>30 \mathrm{~kg} / \mathrm{m}^{2}$, and a female and a male group. Infectious complications were observed for 31 days after admission. Data are given as mean \pm standard errors of the means. Analysis of variance, Kruskal-Wallis test, $\chi^{2}$ tests, and Pearson's correlation were used for the analyses and the significance level was set at $P<0.05$.

Results The overall infection rates were $31.0 \%$ in the BMI $<25 \mathrm{~kg} / \mathrm{m}^{2}$ group, $29.0 \%$ in the BMI $25-30 \mathrm{~kg} / \mathrm{m}^{2}$ group, and $24.5 \%$ in the $\mathrm{BMI}>30 \mathrm{~kg} / \mathrm{m}^{2}$ group
\end{abstract}

\section{Mica $(\bowtie) \cdot$ M. Plecko}

Division of Trauma Surgery, University Hospital Zürich, 8091 Zürich, Switzerland

e-mail: ladislav.mica@usz.ch

\section{Keller}

Department of Neurology, University Hospital of Cologne, Cologne, Germany

J. Vomela

Department of Thoracic Surgery, University Hospital Brno, Brno, Czech Republic

\section{O. Trentz}

Former Head of the Department of Trauma Surgery,

University Hospital Zürich, Zürich, Switzerland

\section{J. Keel}

University Hospital of Orthopedic Surgery, Inselspital Bern, Bern, Switzerland
$(P=0.519)$. The female patients developed significantly fewer infectious complications than the male patients (26.8 vs. $73.2 \% ; P<0.001)$. The incidence of death was significantly decreased according to the BMI group ( 8.8 vs. 7.2 vs. $1.5 \% ; P<0.0001)$ and the female population had a significantly lower mortality rate (4.1 vs. $13.4 \%$; $P<0.0001)$. Pearson's correlations between the Abbreviated Injury Scale (AIS) score and the corresponding infectious foci were not significant.

Conclusion Higher BMI seems to be protective against polytrauma-associated death but not polytrauma-associated infections, and female gender protects against both polytrauma-associated infections and death. Understanding gender-specific immunomodulation could improve the outcome of polytrauma patients.

Keywords Body mass index - Gender - Polytrauma . Infection · ISS

\section{Introduction}

Different results have been reported for the association between body mass index (BMI) and polytrauma [1, 2]. BMI is an anthropometric index defining the weight-toheight relationship, and is expressed as the weight of the individual in kilograms divided by the square of his/her height in meters $\left(\mathrm{kg} / \mathrm{m}^{2}\right)$. Individuals with normal weight have BMIs between 18.5 and $24.9 \mathrm{~kg} / \mathrm{m}^{2}$; overweight is defined as BMI $\geq 25 \mathrm{~kg} / \mathrm{m}^{2}$ and obesity as BMI $\geq 30 \mathrm{~kg} /$ $\mathrm{m}^{2}$. BMI values are age- and sex-independent [3], and obesity is known to be one of the most significant risk factors for diseases such as cancer, heart disease, and diabetes mellitus in Western-oriented countries, called the metabolic syndrome [4]. To date, the association between 
chronic diseases and obesity seems to be clear, but the impact of obesity on patients' immunity in critical care settings after polytrauma remains unclear [2,5]. It is also a well-known fact that overweight people have a higher incidence in infectious viral diseases such as pandemic influenza $\mathrm{A}(\mathrm{H} 1 \mathrm{~N} 1)$, but the question remains as to whether it is caused by obesity itself or by its secondary effects, such as obstructive ventilation [6]. Obesity not only hinders nursing procedures, but also negatively affects airway management, and makes surgical exposure more difficult and radiographic imaging less feasible and less reliable [7]. However, one report claimed that overweight, obese, and severely obese patients in critical care showed reduced mortality and improved functional status after discharge from hospital-whether it was due to the energy storage of fatty tissue in a catabolic intensive care unit (ICU) stay remains speculative [8]. This seems to contradict data from population- and disease-based studies and a plethora of data from the critical care literature [9-13]. Those studies have shown that severely obese victims of blunt trauma deteriorate rapidly and are less responsive to interventions. Furthermore, obesity is recognized as an independent predictor of mortality in such patients, who are also reported to have an increased risk of multi-organ failure [2, 14]. BMI is reported to be a predictor of injury pattern and a BMI $>30 \mathrm{~kg} / \mathrm{m}^{2}$ significantly predicted the development of pulmonary problems and rib and pelvic fractures in patients after blunt trauma [15]. On the other hand, there might be also some protective effect of the fatty tissue by its aromatase activity, converting the 4-androstenedione to estradiol-17 $\beta$ [16]. This might lead to a partial feminization of the obese patient and, thus, to a reduced incidence in infectious complications. There is high evidence that female patients are positively protected against infectious complications [17-20]. Whether this 'female advantage' in reality has an effect on the incidence of infectious complications in polytrauma patients has not yet been tested. However, the protective effect of estradiol-17 $\beta$ produced by female patients and possibly obese patients is a wellknown fact [17-20]. In this study, the focus was placed on the gender- and BMI-specific incidence of infections in polytrauma patients.

\section{Patients and methods}

Patients and ethics

A total of 651 patients with polytrauma admitted to the emergency room of the University Hospital Zürich in the period 1996-2008 were included in this study. The inclusion criteria were an Injury Severity Score (ISS) $\geq 16$ points, age $\geq 16$ years, and admission within at least $24 \mathrm{~h}$ of incurring polytrauma (ISS $\geq 16$ ). The population was subdivided into three groups (Table 1a), BMI $<25 \mathrm{~kg} / \mathrm{m}^{2}$, BMI $25-30 \mathrm{~kg} / \mathrm{m}^{2}$, and BMI $>30 \mathrm{~kg} / \mathrm{m}^{2}$, and males and females. The minimal acceptable BMI was $18.5 \mathrm{~kg} / \mathrm{m}^{2}$. The observation period was 31 days. All patient data were collected retrospectively. All data were retrieved from patient records with the approval of the local institutional review board (IRB) according to the University of Zürich IRB guidelines, as well as the World Medical Association (WMA) Declaration of Helsinki and the study was conducted according to the guidelines for good clinical practice ("Retrospektive Analysen in der Chirurgischen Intensivmedizin" Nr. StV 01-2008).

\section{Diagnostic protocol}

All hemodynamically stable patients admitted to the trauma bay underwent an immediate whole-body computed tomography (CT) scan. Hemodynamically unstable patients underwent resuscitative procedures according to the Advanced Trauma Life Support ${ }^{\circledR}$ (ATLS ${ }^{\circledR}$ ) standards, with a subsequent whole-body CT scan.

\section{Primary care}

The primary treatment of all patients admitted was according to the ATLS ${ }^{\circledR}$ guidelines and the previously assessed trauma management protocol after appropriate indications were identified [21, 22]. Briefly, after airway intubation, ventilation, and cardiovascular management, life-saving surgery was performed with decompression of the body cavities, control of any hemorrhage, and the identification of any contaminated tissues. The first surgical interventions were followed by the stabilization of major fractures and the radical debridement of necrotic tissues.

\section{Trauma scoring systems}

The ISS and the New Injury Severity Score (NISS) were used to define the severity of the trauma based on the Abbreviated Injury Scale (AIS) score [23-25]. The Acute Physiology and Chronic Health Evaluation II (APACHE II) score was used to evaluate the overall physiological impairment of the patient [26].

\section{Definition of infection}

Infection was defined as the invasion and multiplication of pathogenic microorganisms in a bodily part or tissue, such as bacteria, viruses, and parasites that are not normally present within the body, which may produce subsequent tissue injury and progress to overt disease through a variety of cellular or toxic mechanisms. An infection may cause no 
Table 1 Characteristics of the patient sample at admission. a Patient sample divided by BMI. b Patient sample divided by gender

\begin{tabular}{|c|c|c|c|c|c|}
\hline Characteristics & Total & BMI $18.5-25 \mathrm{~kg} / \mathrm{m}^{2}$ & BMI $25-30 \mathrm{~kg} / \mathrm{m}^{2}$ & $\mathrm{BMI}>30 \mathrm{~kg} / \mathrm{m}^{2}$ & $P$-value \\
\hline \multicolumn{6}{|l|}{ a } \\
\hline Patients $(N)$ & 651 & 378 & 224 & 49 & \\
\hline Age (years) & $42.9 \pm 0.75$ & $42.9 \pm 1.0$ & $43.4 \pm 1.3$ & $44.3 \pm 2.4$ & $0.715^{*}$ \\
\hline Sex male/female $(N)$ & $495 / 156$ & $264 / 114$ & $191 / 33$ & $40 / 9$ & $<0.0001^{\dagger}$ \\
\hline BMI $\left(\mathrm{kg} / \mathrm{m}^{2}\right)$ & $24.7 \pm 0.1$ & $22.3 \pm 0.1$ & $27.0 \pm 0.1$ & $32.7 \pm 0.6$ & $<0.0001 *$ \\
\hline AIS head & $3.9 \pm 0.1$ & $4.0 \pm 0.1$ & $4.0 \pm 0.1$ & $3.8 \pm 0.3$ & $0.841 *$ \\
\hline AIS face & $2.1 \pm 0.1$ & $2.1 \pm 0.1$ & $2.2 \pm 0.1$ & $1.9 \pm 0.3$ & $0.568 *$ \\
\hline AIS thorax & $3.2 \pm 0.0$ & $3.2 \pm 0.1$ & $3.2 \pm 0.1$ & $3.5 \pm 0.2$ & $0.131 *$ \\
\hline AIS abdomen & $4.1 \pm 0.1$ & $4.1 \pm 0.1$ & $4.1 \pm 0.1$ & $4.3 \pm 0.2$ & $0.646^{*}$ \\
\hline AIS spine & $3.1 \pm 0.1$ & $3.1 \pm 0.1$ & $3.1 \pm 0.2$ & $3.3 \pm 0.3$ & $0.825 *$ \\
\hline AIS extremities & $2.7 \pm 0.1$ & $2.7 \pm 0.1$ & $2.6 \pm 0.1$ & $2.7 \pm 0.1$ & $0.876^{*}$ \\
\hline AIS pelvis & $2.8 \pm 0.1$ & $2.8 \pm 0.1$ & $2.7 \pm 0.1$ & $2.5 \pm 0.2$ & $0.193 *$ \\
\hline AIS skin & $1.7 \pm 0.1$ & $1.7 \pm 0.1$ & $1.7 \pm 0.1$ & $2.0 \pm 0.3$ & $0.569 *$ \\
\hline ISS & $29.6 \pm 0.5$ & $28.9 \pm 0.7$ & $30.1 \pm 1.0$ & $32.8 \pm 1.8$ & $0.147 *$ \\
\hline NISS & $40.1 \pm 0.6$ & $39.2 \pm 0.8$ & $41.0 \pm 1.1$ & $43.4 \pm 2.3$ & $0.160 *$ \\
\hline APACHE II & $16.9 \pm 0.4$ & $16.9 \pm 0.5$ & $17.0 \pm 0.6$ & $15.5 \pm 1.2$ & $0.583 *$ \\
\hline Hemoglobin (g/L) & 10.60 .1 & $10.8 \pm 0.2$ & $10.7 \pm 0.3$ & $9.4 \pm 0.5$ & $0.056^{*}$ \\
\hline Base excess $(\mathrm{mmol} / \mathrm{L})$ & $-2.8 \pm 0.4$ & $-2.3 \pm 0.6$ & $-3.4 \pm 0.6$ & $-4.1 \pm 1.6$ & $0.276^{*}$ \\
\hline Lactate $(\mathrm{mmol} / \mathrm{L})$ & $3.5 \pm 0.3$ & $3.5 \pm 0.4$ & $3.5 \pm 0.2$ & $3.5 \pm 0.5$ & $0.990 *$ \\
\hline $\mathrm{pH}$ & $7.3 \pm 0.0$ & $7.2 \pm 0.0$ & $7.3 \pm 0.0$ & $7.3 \pm 0.0$ & $0.427 *$ \\
\hline Prothrombin time (\%) & $77.9 \pm 1.0$ & $76.1 \pm 1.4$ & $81.0 \pm 1.6$ & $76.5 \pm 3.9$ & $0.073 *$ \\
\hline Platelets $\left(10^{3} / \mu \mathrm{L}\right)$ & $189.7 \pm 3.9$ & $189.8 \pm 5.1$ & $193.5 \pm 6.7$ & $171.7 \pm 10.9$ & $0.356^{*}$ \\
\hline \multicolumn{2}{|l|}{ Characteristics } & Male & Female & & $P$-value \\
\hline $\mathrm{b}$ & & & & & \\
\hline Patients $(N)$ & & 495 & 156 & & $<0.0001^{\dagger}$ \\
\hline Age (years) & & $40.0 \pm 0.8$ & $45.7 \pm$ & & $<0.0001 *$ \\
\hline BMI $\left(\mathrm{kg} / \mathrm{m}^{2}\right)$ & & $25.3 \pm 0.2$ & $24.1 \pm$ & & $<0.0001 *$ \\
\hline AIS head & & $3.6 \pm 0.1$ & $3.7 \pm($ & & $0.352 *$ \\
\hline AIS face & & $2.2 \pm 0.1$ & $2.2 \pm$ & & $0.254 *$ \\
\hline AIS thorax & & $3.2 \pm 0.1$ & $3.3 \pm($ & & $0.657^{*}$ \\
\hline AIS abdomen & & $4.0 \pm 0.1$ & $4.2 \pm$ & & $0.106 *$ \\
\hline AIS spine & & $3.1 \pm 0.1$ & $2.8 \pm$ & & $0.211 *$ \\
\hline AIS extremities & & $2.8 \pm 0.1$ & $2.8 \pm$ & & $0.739 *$ \\
\hline AIS pelvis & & $2.9 \pm 0.1$ & $2.7 \pm($ & & $0.071 *$ \\
\hline AIS skin & & $1.6 \pm 0.1$ & $1.5 \pm($ & & $0.486^{*}$ \\
\hline ISS & & $28.4 \pm 0.5$ & $28.3 \pm$ & & $0.968^{*}$ \\
\hline NISS & & $38.1 \pm 0.7$ & $38.8 \pm$ & & $0.668^{*}$ \\
\hline APACHE II & & $14.3 \pm 0.4$ & $15.5 \pm$ & & $0.135 *$ \\
\hline Hemoglobin (g/L) & & $11.3 \pm 0.2$ & $10.1 \pm$ & & $<0.0001^{*}$ \\
\hline Base excess $(\mathrm{mmol} / \mathrm{L})$ & & $-2.9 \pm 0.4$ & $-2.9 \pm$ & & $0.989 *$ \\
\hline Lactate $(\mathrm{mmol} / \mathrm{L})$ & & $3.1 \pm 0.1$ & $2.8 \pm$ & & $0.372 *$ \\
\hline $\mathrm{pH}$ & & $7.3 \pm 0.2$ & $7.3 \pm($ & & $0.237 *$ \\
\hline Prothrombin time (\%) & & $78.3 \pm 1.1$ & $79.5 \pm$ & & $0.605 *$ \\
\hline Platelets $\left(10^{3} / \mu \mathrm{L}\right)$ & & $195.1 \pm 4.1$ & $199.5=$ & & $0.623 *$ \\
\hline
\end{tabular}

All BMI values are in $\mathrm{kg} / \mathrm{m}^{2}$. Only 14 patients met the criterion for being underweight $(\mathrm{BMI}<18.5)$ and were excluded. Data are given as mean $\pm \mathrm{SEM}$ AIS Abbreviated Injury Scale, ISS Injury Severity Score, NISS New Injury Severity Score, APACHE II Acute Physiology and Chronic Health Evaluation II * ANOVA

$\dagger \chi^{2}$ test 
symptoms and be subclinical, or it may cause symptoms and be clinically apparent. Microorganisms that live naturally in the body were not considered to constitute an infection. All infections had to be proved by a positive microbial culture.

\section{Laboratory parameters}

Lactate, $\mathrm{pH}$, and hematocrit were measured at regular intervals with a blood-gas analyzer (ABL800 Flex; Radiometer Switzerland, GmbH, Thalwil, Switzerland). Platelets were measured with flow cytometry (FACSCalibur; Becton-Dickinson, Allschwil, Switzerland). The prothrombin time was measured with a standard method described previously [27].

\section{Statistical analysis}

Data are presented as the mean \pm standard errors of the means (SEM) for continuous variables and as percentages for categorical variables. The data for the BMI groups were compared using the Kruskal-Wallis and $\chi^{2}$ tests for categorical data and with analysis of variance (ANOVA) for continuous data. Pearson's correlation was used to determine the dependency of the data sets. $P<0.05$ was to be considered significant. The data were analyzed using the SPSS statistical software (version 21.0; IBM, Armonk, NY, USA).

\section{Results}

Patient sample

All BMI data given below are reported in $\mathrm{kg} / \mathrm{m}^{2}$, but the units are not included for simplicity of presentation. A total of 651 patients met the inclusion criteria; 378 of them were non-obese, with a $\mathrm{BMI}<25 ; 224$ were overweight, with a BMI 25-30; and 49 were obese, with a BMI $>30$. Of these patients, 495 were male and 156 were female, with significantly more men in all three groups $(P<0.0001$; Table 1a). The overall mean BMI was $24.7 \pm 0.1$. The mean age was $42.9 \pm 0.75$ years, and did not differ significantly according to BMI (BMI $<25,42.9 \pm 1.0$ years; BMI 25-30, $43.4 \pm 1.3$ years; and BMI $>30$, $44.3 \pm 2.4$ years; $P=0.715 ; \quad$ Table 1 a). The female patients had a significantly lower BMI $(25.3 \pm 0.2$ vs. $24.1 \pm 0.3$, male vs. female; $P<0.0001$ ). The female sample was significantly older than the male sample $(40.0 \pm 0.8$ vs. $45.7 \pm 1.6$ years, male vs. female; $P<0.0001)$. There were no other differences found except for significantly lower hemoglobin in the female sample on admission (Table 1b). Only 14 patients (four males and ten females) met the criteria for being underweight $($ BMI $<18.5)$ and were excluded from the study. All patients admitted to the trauma bay who met the inclusion criteria were included in the study.

Injury patterns

The analysis of the injury patterns according to the AIS revealed no significant differences between the BMI groups. In this patient sample, there were no differences between the three groups in the ISS, NISS, or APACHE II scores (Table 1a). The gender-specific analysis revealed no significant differences in the injury pattern or physiological parameters on admission (Table 1b).

Incidence of infection

There were no significant differences between the three BMI groups in the incidence of infection (Table 2a). However, the female sample revealed a significantly lower incidence of infectious complications in all anatomical region after polytrauma compared with the male population $(P<0.001)$ (Table 2b).

Correlation of injury pattern and infection

Pearson's correlation revealed no significant association between the injury pattern and the infectious focus. The correlation coefficient was always negative or below 0.1 . There was absolutely no correlation between the severity of an injury in an anatomical region and the incidence of infection in that region (Table 3).

\section{Outcomes}

Patients with a higher BMI revealed a significantly lower mortality rate (BMI $<25,8.8 \%$; BMI $25-30,7.2 \%$; and BMI $>30,1.5 \% ; P<0.0001$ ) (Table 4a). The female patients showed a significantly lower mortality compared to the male sample (13.4 vs. $4.1 \%$, male vs. female; $P<0.0001$ ) (Table 4b). There were no significant differences found between hospitalization, intensive care stay, or ventilation in all BMI groups and in the male and female samples (Table 4a, b).

\section{Discussion}

This study was designed to evaluate the impact of BMI and gender on the development of infectious complications in patients with polytrauma. Understanding the altered physiology of obese patients with polytrauma can play a pivotal role in their multidisciplinary treatment. In 
Table 2 a Patient sample divided by BMI. b Patient sample divided by gender

\begin{tabular}{|c|c|c|c|c|c|c|c|c|c|c|c|}
\hline \multicolumn{2}{|c|}{ BMI group } & Infection & $\begin{array}{l}\text { CNS } \\
\text { infection }\end{array}$ & \multicolumn{2}{|c|}{ Pneumonia } & $\begin{array}{l}\text { Abdominal } \\
\text { infection }\end{array}$ & $\begin{array}{l}\text { Urinary tract } \\
\text { infection }\end{array}$ & $\begin{array}{l}\text { Wound } \\
\text { infection }\end{array}$ & $\begin{array}{l}\text { Catheter } \\
\text { infection }\end{array}$ & Male & Female \\
\hline \multicolumn{12}{|l|}{$\mathrm{a}$} \\
\hline \multicolumn{2}{|c|}{$18.5-25 \mathrm{~kg} / \mathrm{m}^{2}$} & $31.0 \%$ & $4.1 \%$ & \multicolumn{2}{|l|}{$17.7 \%$} & $2.4 \%$ & $4.5 \%$ & $7.1 \%$ & $6.6 \%$ & $69.8 \%$ & $30.2 \%$ \\
\hline \multicolumn{2}{|c|}{$25-30 \mathrm{~kg} / \mathrm{m}^{2}$} & $29.0 \%$ & $3.5 \%$ & \multicolumn{2}{|l|}{$15.6 \%$} & $0.4 \%$ & $3.5 \%$ & $7.1 \%$ & $4.9 \%$ & $85.3 \%$ & $14.7 \%$ \\
\hline \multicolumn{2}{|c|}{$>30 \mathrm{~kg} / \mathrm{m}^{2}$} & $24.5 \%$ & $4.0 \%$ & \multicolumn{2}{|l|}{$12.2 \%$} & $2.0 \%$ & $10.2 \%$ & $4.1 \%$ & $6.1 \%$ & $81.6 \%$ & $18.4 \%$ \\
\hline \multicolumn{2}{|l|}{ Total } & $29.8 \%$ & $4.0 \%$ & \multicolumn{2}{|l|}{$16.6 \%$} & $1.7 \%$ & $4.6 \%$ & $6.9 \%$ & $6.0 \%$ & $76.0 \%$ & $24 \%$ \\
\hline \multicolumn{2}{|l|}{$P$-value } & $0.519 *$ & $0.924 *$ & \multicolumn{2}{|l|}{$0.438 *$} & $0.172 *$ & $0.146^{*}$ & $0.667 *$ & $0.563^{*}$ & $<0.001 *$ & $<0.001 *$ \\
\hline Gender & Infection & CNS & ection & Pneumonia & $\mathrm{Abc}$ & minal infection & Urinary trac & nfection & Wound infectior & Cathe & infection \\
\hline \multicolumn{12}{|l|}{ 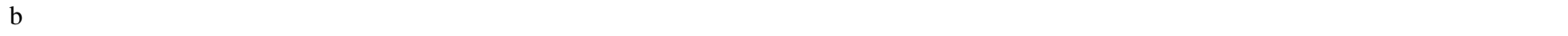 } \\
\hline Male & $33.1 \%$ & \multicolumn{2}{|c|}{$5.1 \%$} & $18.2 \%$ & \multicolumn{2}{|c|}{$2.1 \%$} & $5.8 \%$ & & $10.4 \%$ & \multicolumn{2}{|c|}{$5.8 \%$} \\
\hline Female & $29.3 \%$ & \multicolumn{2}{|l|}{$3.5 \%$} & $16.5 \%$ & 0.6 & & $4.2 \%$ & & $5.9 \%$ & $4.4 \%$ & \\
\hline Total & $29.8 \%$ & $4.0 \%$ & & $16.6 \%$ & 1.7 & & $4.6 \%$ & & $6.9 \%$ & $6.0 \%$ & \\
\hline$P$-value & $<0.001 *$ & $<0.00$ & & $<0.001 *$ & $<0$ & $01 *$ & $<0.001^{*}$ & & $<0.001^{*}$ & $<0.00$ & \\
\hline
\end{tabular}

Data represent the incidence of infectious complications in patients after polytrauma over an observation period of 31 days. Data are given as percentages of the respective groups

CNS central nervous system

* Kruskal-Wallis test within the BMI and gender groups

Table 3 Pearson's correlation between the incidence of infectious complications and the injury severity in the corresponding anatomical region

\begin{tabular}{|c|c|c|c|c|c|c|c|c|}
\hline $\begin{array}{l}P \text {-value* } \\
\text { Pearson's correlation }\end{array}$ & AIS head & AIS face & AIS thorax & AIS abdomen & AIS spine & AIS extremities & AIS pelvis & AIS skin \\
\hline \multirow[t]{2}{*}{ Infection } & 0.476 & 0.588 & 0.351 & 0.345 & 0.966 & 0.734 & 0.775 & 0.079 \\
\hline & -0.029 & -0.022 & -0.037 & -0.038 & 0.002 & -0.014 & 0.011 & -0.070 \\
\hline \multirow[t]{2}{*}{ CNS infection } & 0.742 & 0.829 & 0.374 & 0.196 & 0.400 & 0.208 & 0.787 & 0.950 \\
\hline & 0.013 & -0.009 & -0.036 & -0.052 & -0.034 & 0.050 & 0.011 & 0.003 \\
\hline \multirow[t]{2}{*}{ Pneumonia } & 0.245 & 0.372 & 0.406 & 0.706 & 0.760 & 0.659 & 0.525 & 0.211 \\
\hline & -0.046 & -0.036 & -0.033 & 0.015 & -0.012 & 0.018 & 0.025 & -0.050 \\
\hline \multirow[t]{2}{*}{ Abdominal infection } & 0.662 & 0.702 & 0.964 & 0.445 & 0.041 & 0.446 & 0.255 & 0.911 \\
\hline & -0.017 & 0.015 & 0.002 & -0.031 & 0.082 & 0.030 & -0.045 & -0.004 \\
\hline \multirow[t]{2}{*}{ Urinary tract infection } & 0.365 & 0.192 & 0.878 & 0.242 & 0.189 & 0.578 & 0.744 & 0.081 \\
\hline & -0.036 & 0.052 & -0.006 & 0.047 & -0.053 & 0.022 & -0.013 & -0.070 \\
\hline \multirow[t]{2}{*}{ Wound infection } & 0.986 & 0.533 & 0.210 & 0.605 & 0.830 & 0.163 & 0.955 & 0.311 \\
\hline & 0.001 & -0.025 & -0.050 & 0.021 & 0.009 & -0.056 & 0.002 & -0.041 \\
\hline \multirow[t]{2}{*}{ Catheter infection } & 0.272 & 0.662 & 0.397 & 0.525 & 0.606 & 0.648 & 0.352 & 0.590 \\
\hline & -0.044 & 0.017 & 0.034 & 0.025 & 0.021 & 0.018 & 0.037 & 0.022 \\
\hline
\end{tabular}

There was a significant correlation between spinal injury severity and abdominal infection, but the correlation coefficient was very low

* ANOVA, Pearson's correlation

AIS Abbreviated Injury Scale, CNS central nervous system

Western-oriented societies, the prevalence of obesity is a growing problem that appears to be altering current medical and surgical treatment strategies [28]. Female gender has a positive immunomodulatory effect on the development of infectious complications after trauma [17-20]. Overweight patients have significantly more comorbidities than normal-weight patients and face more post-traumatic complications [29, 30]. In this study, the incidence of infections was analyzed over a period of 31 days after polytrauma. The ISS did not differ between the study groups. The incidence of infectious complications also did not differ with increasing BMI scores over the observation period. On one hand, the production of estrogen by aromatase activity in adipocytes is a well-known phenomenon [16]. The steroid pathway then shifts from the production of 4-androstenedione and testosterone toward the 
Table 4 Outcomes of the study sample. a Patient sample divided by BMI. b Patient sample divided by gender

\begin{tabular}{|c|c|c|c|c|c|}
\hline Outcome & Total & BMI $18.5-25 \mathrm{~kg} / \mathrm{m}^{2}$ & BMI $25-30 \mathrm{~kg} / \mathrm{m}^{2}$ & BMI $>30 \mathrm{~kg} / \mathrm{m}^{2}$ & $P$-value \\
\hline \multicolumn{6}{|l|}{ a } \\
\hline Death $[N,(\%$ of all $)]$ & $114(17.5 \%)$ & $57(8.8 \%)$ & $47(7.2 \%)$ & $10(1.5 \%)$ & $<0.0001 *$ \\
\hline Hospitalization (days) & $18.9 \pm 1.1$ & $20.0 \pm 1.6$ & $17.2 \pm 1.3$ & $18.5 \pm 3.1$ & $0.473^{\dagger}$ \\
\hline Intensive care (days) & $9.8 \pm 0.5$ & $9.9 \pm 0.6$ & $9.5 \pm 0.7$ & $10.7 \pm 2.4$ & $0.813^{\dagger}$ \\
\hline Ventilation (days) & $6.2 \pm 0.4$ & $6.3 \pm 0.5$ & $5.8 \pm 0.5$ & $7.5 \pm 2.4$ & $0.508^{\dagger}$ \\
\hline Outcome & \multicolumn{2}{|c|}{ Total } & & Female & $P$-value \\
\hline \multicolumn{6}{|l|}{$\mathrm{b}$} \\
\hline Death $[N,(\%$ of all $)]$ & \multicolumn{2}{|c|}{$114(17.5 \%)$} & $\%)$ & $27(4.1 \%)$ & $<0.0001 * *$ \\
\hline Hospitalization (days) & \multicolumn{2}{|c|}{$18.9 \pm 1.1$} & & $26.3 \pm 1.8$ & $0.705^{\dagger}$ \\
\hline Intensive care (days) & \multicolumn{2}{|c|}{$9.8 \pm 0.5$} & & $10.9 \pm 0.9$ & $0.485^{\dagger}$ \\
\hline Ventilation (days) & \multicolumn{2}{|c|}{$6.2 \pm 0.4$} & & $5.8 \pm 0.6$ & $0.180^{\dagger}$ \\
\hline
\end{tabular}

production of estrone and estradiol-17 $\beta$. Feminine steroids are highly protective against inflammatory reactions [27]. The data presented here indicate no difference in the incidence of infections in the overweight patients in this study. The production of estradiol-17 $\beta$ produced by the adipocytes seems not to be effective enough for the 'feminine protection' against infectious complications. However, the feminine gender was significantly protected against infectious complications without differences in injury severity or pre-existing diseases reflected by the ISS and APACHE II scores. The question as to whether the injury pattern correlates to a specific anatomical region seems to be negatively answered. There was no correlation between the injured anatomical region and an infection within that anatomical region, so the injury itself did not constitute an infectious focus. Only spinal injuries and abdominal infections correlated significantly, but with a low correlation coefficient. This may suggest a random association. On the other hand, polytrauma patients face a catabolic state early, with consumption of the body's energy reserves, decreasing the functionality of the immunity system. A slightly elevated BMI may provide enough energy in a polytrauma situation to keep the immunity system functional, which is mirrored in the better survival rate according to the increasing BMI. Taking all the findings together, the outcomes of the overweight patients were not better than those of the normal-weight patients, but the mortality rate decreased significantly in the overweight BMI group and in the female group. It can be stated definitively that females are protected against infectious complications in polytrauma conditions, whereas the overweight and obese patients are not. Further analyses that include the assessment of hormonal status and precise measurements of body fat might be more conclusive. The knowledge of hormonal immunomodulation could improve the outcome of severe infections and sepsis in polytrauma patients.

Conflict of interest L. Mica, C. Keller, J. Vomela, O. Trentz, M. Plecko and M. J. Keel declare that they have no conflict of interest.

Compliance with Ethics Guidelines This article does not contain any studies with human or animal subjects performed by the any of the authors. All patient data were collected retrospectively. All data were retrieved from patient records with the approval of the local institutional review board (IRB) according to the University of Zürich IRB guidelines, as well as the World Medical Association (WMA) Declaration of Helsinki and the study was conducted according to the guidelines for good clinical practice ("Retrospektive Analysen in der Chirurgischen Intensivmedizin" Nr. StV 01-2008).

\section{References}

1. Maheshwari R, Mack CD, Kaufman RP, Francis DO, Bulger EM, Nork SE, Henley MB. Severity of injury and outcomes among obese trauma patients with fractures of the femur and tibia: a crash injury research and engineering network study. J Orthop Trauma. 2009;23:634-9.

2. Neville AL, Brown CV, Weng J, Demetriades D, Velmahos GC. Obesity is an independent risk factor of mortality in severely injured blunt trauma patients. Arch Surg. 2004;139:983-7.

3. World Health Organization (WHO). Global database on body mass index, 2004 (updated March 2011). 2012. http://apps.who. int/bmi/index.jsp. Accessed 30 Sep 2012.

4. Calle EE, Thun MJ, Petrelli JM, Rodriguez C, Heath CW Jr. Body-mass index and mortality in a prospective cohort of U.S. adults. N Engl J Med. 1999;341:1097-105. 
5. Byrnes MC, McDaniel MD, Moore MB, Helmer SD, Smith RS. The effect of obesity on outcomes among injured patients. J Trauma. 2005;58:232-7.

6. Milner JJ, Beck MA. The impact of obesity on the immune response to infection. Proc Nutr Soc. 2012;71:298-306.

7. Boulanger BR, Milzman DP, Rodriguez A. Obesity. Crit Care Clin. 1994;10:613-22.

8. Tremblay A, Bandi V. Impact of body mass index on outcomes following critical care. Chest. 2003;123:1202-7.

9. Troiano RP, Frongillo EA Jr, Sobal J, Levitsky DA. The relationship between body weight and mortality: a quantitative analysis of combined information from existing studies. Int $\mathbf{J}$ Obes Relat Metab Disord. 1996;20:63-75.

10. Milzman DP, Boulanger BR, Rodriguez A, Soderstrom CA, Mitchell KA, Magnant CM. Pre-existing disease in trauma patients: a predictor of fate independent of age and injury severity score. J Trauma. 1992;32:236-43.

11. Hoit BD, Gilpin EA, Maisel AA, Henning H, Carlisle J, Ross J Jr. Influence of obesity on morbidity and mortality after acute myocardial infarction. Am Heart J. 1987;114:1334-41.

12. Galanos AN, Pieper CF, Kussin PS, Winchell MT, Fulkerson WJ, Harrell FE Jr, Teno JM, Layde P, Connors AF Jr, Phillips RS, Wenger NS. Relationship of body mass index to subsequent mortality among seriously ill hospitalized patients. SUPPORT Investigators. The Study to Understand Prognoses and Preferences for Outcome and Risks of Treatments. Crit Care Med. 1997;25:1962-8.

13. Marik P, Varon J. The obese patient in the ICU. Chest. 1998;113: 492-8.

14. Ciesla DJ, Moore EE, Johnson JL, Burch JM, Cothren CC, Sauaia A. Obesity increases risk of organ failure after severe trauma. J Am Coll Surg. 2006;203:539-45.

15. Choban PS, Weireter LJ Jr, Maynes C. Obesity and increased mortality in blunt trauma. J Trauma. 1991;31:1253-7.

16. Ackerman GE, Smith ME, Mendelson CR, MacDonald PC, Simpson ER. Aromatization of androstenedione by human adipose tissue stromal cells in monolayer culture. J Clin Endocrinol Metab. 1981;53:412-7.

17. Choudhry MA, Bland KI, Chaudry IH. Trauma and immune response-effect of gender differences. Injury. 2007;38:1382-91.

18. Angele MK, Schwacha MG, Ayala A, Chaudry IH. Effect of gender and sex hormones on immune responses following shock. Shock. 2000;14:81-90.

19. Choudhry MA, Chaudry IH. Gender dimorphism and use of sex steroid/receptor antagonist after trauma. In: Welsh CJ, Meagher MW, Sternberg EM, editors. Neural and neuroendocrine mechanisms in host defense and autoimmunity. New York: Springer; 2006. p. 101-21.

20. Choudhry MA, Schwacha MG, Hubbard WJ, Kerby JD, Rue LW, Bland KI, Chaudry IH. Gender differences in acute response to trauma-hemorrhage. Shock. 2005;24:101-6.

21. Ertel W, Trentz O. Causes of shock in the severely traumatized patient: emergency treatment. In: Goris RJA, Trentz O, editors. The integrated approach to trauma care: the first 24 hours. Berlin: Springer; 1995. p. 78-87.

22. Trentz O, Friedl HP. Therapeutic sequences in the acute period in unstable patients. In: Goris RJA, Trentz O, editors. The integrated approach to trauma care: the first 24 hours. Berlin: Springer; 1995. p. 172-8.

23. Baker SP, O'Neill B, Haddon W Jr, Long WB. The injury severity score: a method for describing patients with multiple injuries and evaluating emergency care. J Trauma. 1974;14: 187-96.

24. Champion HR, Copes WS, Sacco WJ, Lawnick MM, Bain LW, Gann DS, Gennarelli T, Mackenzie E, Schwaitzberg S. A new characterization of injury severity. J Trauma. 1990;30:539-45.

25. Gennarelli TA, Wodzin E, editors. The Abbreviated Injury Scale 2005. Barrington: Association for the Advancement of Automotive Medicine; 2005.

26. Knaus WA, Draper EA, Wagner DP, Zimmerman JE. APACHE II: a severity of disease classification system. Crit Care Med. 1985;13:818-29.

27. Jackson CM, White GC 2nd, Barrowcliffe T, Esnouf MP, Jespersen J, Kluft C, Lenahan J; Joint Committee of the IFCC Scientific Division and the ISTH Scientific and Standardization Committee. A reference system approach to future standardization of laboratory tests for hemostasis. A position paper of the Joint Committee of the IFCC Scientific Division and the ISTH Scientific and Standardization Committee. Thromb Haemost. 2002;87:165-9.

28. Quesenberry CP Jr, Caan B, Jacobson A. Obesity, health services use, and health care costs among members of a health maintenance organization. Arch Intern Med. 1998;158:466-72.

29. Hoffmann M, Lefering R, Gruber-Rathmann M, Rueger JM, Lehmann W; Trauma Registry of the German Society for Trauma Surgery. The impact of BMI on polytrauma outcome. Injury. 2012;43:184-8.

30. Brown CV, Neville AL, Rhee P, Salim A, Velmahos GC, Demetriades D. The impact of obesity on the outcomes of 1,153 critically injured blunt trauma patients. J Trauma. 2005;59: 1048-51. 